\title{
Modeling of the temperature field generated by the deposition of weld bead on a steel butt joint by FEM techniques and thermographic images.
}

\author{
Eduardo José Fernandes Rocha ${ }^{*}$, Tiago de Sousa Antonino ${ }^{b}$, Pablo Batista Guimarães ${ }^{b}$, Ricardo \\ Artur Sanguinetti Ferreira ${ }^{a}$,José Maria Andrade Barbosa ${ }^{a}$, Janardan Rohatgi ${ }^{a}$ \\ ${ }^{a}$ Departamento de Engenharia Mecânica, Universidade Federal de Pernambuco - UFPE, Av. da \\ Arquitetura, Cidade Universitária, 50740-550, Recife, PE, Brasil. \\ ${ }^{b}$ Instituto Federal de Pernambuco - IFPE, Av. Prof. Luís Freire, 500, Cidade Universitária, 50740-540, \\ Recife, PE, Brasil
}

Received: October 25, 2016; Revised: February 01, 2018; Accepted: February 07, 2018

\begin{abstract}
The aim of this work is to predict the temperature field generated by welding a steel butt joint (API $5 \mathrm{~L} \mathrm{X80).} \mathrm{The} \mathrm{prediction} \mathrm{was} \mathrm{modeled} \mathrm{by} \mathrm{finite} \mathrm{element} \mathrm{software} \mathrm{Abaqus} \mathrm{where} \mathrm{the} \mathrm{subroutine} \mathrm{was}$ developed in Fortran so that heat source motion may be included. The motion was based on the Goldak's double ellipsoid. In the model material nonlinearities were included such as thermophysical properties (coefficient of thermal expansion, specific heat, thermal diffusivity and thermal conductivity), which are dependent on temperature and latent heat, heat exchange by convection and radiation and mechanical boundary conditions. The thermal field predicted by the model was validated by infrared thermography. GMAW simulations with the use of an "evenmatched" solid wire (filler metal) carried out the welding process. The results obtained from the numerical model and thermography were in good agreement.
\end{abstract}

Keywords: Numerical modeling, infrared thermography, temperature field, API 5 L X80 steel welding..

\section{Introduction}

Welding is one of the most commonly used manufacturing processes in various branches of industrial activity, such as petrochemical, automotive, shipbuilding, and nuclear industries, among others. The occurrences of the so called thermal stresses generated by the strong thermal gradient in welding promotes geometric distortions and the generation of non-uniform internal stresses (residual stresses). These stresses are undesirable since they downgrade the quality of the welded components ${ }^{1,2}$.

The determination of residual stresses in welded pipelines may be accomplished by experimental procedures such as hole drilling, X-ray diffraction, neutron diffraction, and ultrasound techniques, which are expensive and sometimes difficult possibly involving destructive or semi-destructive procedures $^{3,4}$.

The biggest challenge in using finite element method (FEM) involves specifying a set of material properties that truly reflect the component behavior. If this set of material properties are specified during the numerical simulation and the mesh is reasonably defined, then the temperature fields and residual stresses help to predict accurately. The capacity to carry out all these operations makes the finite element method an effective tool, Yaghi et al. ${ }^{4}$ and the results are similar to those obtained from the infrared system (IR), since it provides direct evidences of transient temperatures and the real boundary conditions of the system under study ${ }^{5}$.
Lee and Chang ${ }^{6}$ found results similar to those obtained in this study and Attarha and Sattari-Far ${ }^{7}$ for carbon steel welding butt joint in the FCAW (Flux Core Arc Welding) and GTAW (Gas Tungsten Arc Welding) processes without any filler metal. The similar behavior was reported by Chiumenti et al. ${ }^{8}$ while studying the temperature field generated by the AISI 304 stainless steel pipe welding with the use of GTAW welding process with addition material. Deng and Murakawa ${ }^{9}$, who used the finite element method to predict the temperature field and residual stress of a thin top joint of a low carbon steel using the GMAW welding process, also obtained similar results. Gery et al. ${ }^{10}$ used the finite element method to simulate the effect of welding speed, welding energy and the Goldak source parameters in the temperature field evolution generated by the welding of a low carbon steel butt joint using the GMAW process. In this work, these factors were found to have a major influence on the MZ (Molten Zone) and HAZ (Heat Affected Zone) sizes, as well as the peak temperatures in the MZ.

Thermography is a technique that allows distinguishing between areas of different temperatures through the detection of infrared radiations emitted by a given body or object subjected to a temperature greater than the absolute zero. The technique becomes an extension of the human vision since it allows visualizing the light in the infrared spectrum ${ }^{11}$.

Currently there are a number of papers published on the numerical determination of the temperature field in welded joints of 
austenitic stainless steels, since in these thermophysical properties does not change as it is not subjected to the phase transformation in the solid state $(\gamma \leftrightarrow \alpha)^{12,13}$. The impact of the temperature and residual stresses is very important to consider in other steels due to the change of the specific volume. In the proposed work on steel API 5L X80 phase transformation and thermophysical properties were considered in the numerical model and the results were validated by the use of infrared thermography.

\section{Experimental Method}

The base material used in this study is API 5L X80 steel pipe with a thickness of $19 \mathrm{~mm}$ and nominal diameter of 864 $\mathrm{mm}$ (34"). The chemical composition is given in Table 1.

The filler metal used was the GMAW solid wire, diameter $1.2 \mathrm{~mm}$, ER70S-6 model ${ }^{14,15}$

Table 1. Chemical composition of the API 5L X80 steel pipe (\% mass)

\begin{tabular}{cccccccc}
\hline $\mathrm{C}$ & $\mathrm{S}$ & $\mathrm{N}$ & $\mathrm{Al}$ & $\mathrm{Si}$ & $\mathrm{P}$ & $\mathrm{Ti}$ & $\mathrm{V}$ \\
\hline 0.03 & 0.003 & 0.0054 & 0.027 & 0.21 & 0.013 & 0.017 & 0.023 \\
$\mathrm{Cr}$ & $\mathrm{Mn}$ & $\mathrm{Ni}$ & $\mathrm{Cu}$ & $\mathrm{Nb}$ & $\mathrm{Mo}$ & $\mathrm{B}$ & $\mathrm{Ca}$ \\
0.158 & 1.78 & 0.013 & 0.008 & 0.071 & 0.183 & 0.0001 & 0.0032 \\
\hline
\end{tabular}

The deposition of the weld bead occurred at a butt joint with a Biesel angle of $45^{\circ}$ along the longitudinal direction of the specimen $(150 \mathrm{~mm} \times 80 \mathrm{~mm} \times 7,5 \mathrm{~mm})$. Table 2 and Figure 1 give the parameters of welding process.

Table 2. Welding parameters used in the experiment.

\begin{tabular}{lc}
\hline Current [A] & 192 \\
Voltage [V] & 18.4 \\
Weld speed [m/s] & 0.00278 \\
Contact tip-to-work distance & 0.0016 \\
(CTWD) [m] & 0.167 \\
Wire feed speed [m/s] & 16 \\
$\begin{array}{l}\text { Shielding gas flow rate }(75 \% \\
\left.\text { Ar+25\% } \mathrm{CO}_{2}\right)[\text { lts/min] }\end{array}$ & $\mathrm{CC}+$ \\
$\begin{array}{l}\text { Polarity } \\
\text { Thermal efficiency of the } \\
\text { process }\end{array}$ & $85 \%$ \\
$\begin{array}{l}\text { Welding average time [sec] } \\
\text { Weld bead length [mm] }\end{array}$ & 36 \\
Weld position & 100 \\
\hline
\end{tabular}

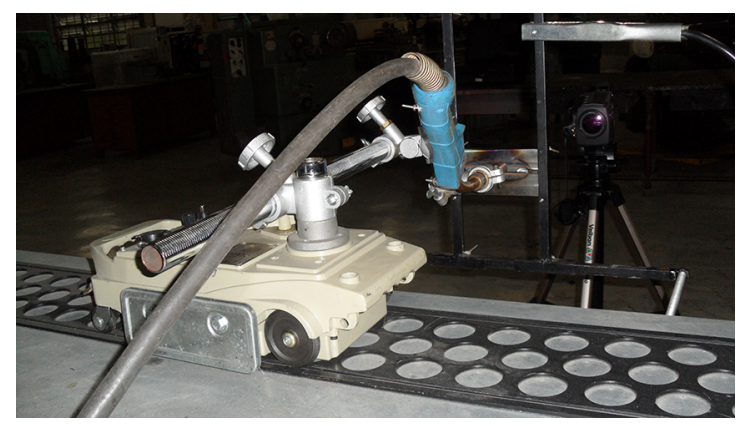

Figure 1. Automated GMAW process utilized in this work

\section{GMAW Finite Element Modeling}

The objective of this simulation is to obtain temperature fields of a welded joint in the GMAW process. In this case a commercial finite element software ABAQUS ${ }^{\circledR}$ is used. However, vaporization of the metal is not taken into consideration but only the fusion process.

Besides consideration of heat transfer due to conduction, the present work also takes into account heat losses due to natural convection and radiation. Variations in the thermophysical properties of the material are considered with the temperature, and this leads to a non-linear analysis, as expressed in Equation 1.

\subsection{Thermal Analysis}

In most of the fusion welding processes, a source of concentrated heat and high intensity is applied and moved along the joint position ${ }^{16}$. Heat conduction through a solid can be expressed ${ }^{17}$ :

$\frac{\partial}{\partial x}\left(K_{T} \frac{\partial T}{\partial x}\right)+\frac{\partial}{\partial y}\left(K_{T} \frac{\partial T}{\partial y}\right)+\frac{\partial}{\partial z}\left(K_{T} \frac{\partial T}{\partial z}\right)+q_{0}=p c_{p} \frac{\partial T}{\partial t}$

In this equation, $\mathbf{T}$ represents temperature, $\mathbf{q}_{0}$ heat source, $\mathbf{x}, \mathbf{y}, \mathbf{z}$ the tri-orthogonal Cartesian coordinates, $\mathbf{t}$ for time, $\mathbf{K}_{\mathrm{T}}$ thermal conductivity, $\boldsymbol{\rho}$ the density and $\mathbf{C}_{\mathbf{p}}$ the specific heat of the material. During the welding operation, the material exchanges heat with the surrounding environment by convection and radiation. Heat losses by convection is represented: $\Phi_{c}=h_{c}\left(T-T_{\infty}\right)$, while heat losses by radiation is expressed: $\phi_{r}=\sigma \varepsilon\left(T^{4}-T_{\infty}^{4}\right)$, where $\mathbf{h}_{\mathbf{c}}$ is the coefficient of convection, $\mathbf{T}$ the surface temperature of the object, $\mathbf{T}_{\infty}$ the temperature of the surrounding fluid $\left(\mathbf{T}_{\infty}=27^{\circ} \mathrm{C}\right), \boldsymbol{\sigma}$ Stefan - Boltzmann constant $\left(\boldsymbol{\sigma}=5,7 \times 10^{-8} \mathrm{Wm}^{-2} \mathrm{~K}^{-4}\right)$ and $\varepsilon$ the emissivity of the object $(\varepsilon=0,91)^{18}$.

The coefficients of thermal expansion $(\boldsymbol{\alpha})$, specific heat $\left(\mathbf{c}_{\mathrm{p}}\right)$, thermal diffusivity $(\boldsymbol{\lambda})$, and thermal conductivity (K) of API 5L X80 steel as a function of temperature were measured experimentally using dilatometry, differential calorimetry scanning and laser flash techniques, and the results are given in Table $3^{19}$.

\subsection{Moving heat source}

The subroutine destined to move the heat source generated by the GMAW torch is called DFLUX, it sequentially applies the heat flow to the nodes as a function of time, according to the selected welding speeds ${ }^{20-22}$. The Goldak double-ellipsoid model was selected for the heat source, Figure 2. The model combines two different ellipsoids, one at the frontal quadrant (2) and the other in the rear quadrant $(3)^{23,24}$. This would represent the energy flow distribution by simulating heat input to the weld joint.

$P_{f}(x, y, z)=f_{f} \eta U I \frac{6 \sqrt{3}}{a_{f} b c \pi^{3 / 2}} e^{\left(\frac{-3 x^{2}}{a_{f}^{2}}\right)} e^{\left(\frac{-3 y^{2}}{b^{2}}\right)} e^{\left(\frac{-3 z^{2}}{c^{2}}\right)}$ 
$P_{r}(x, y, z)=f_{r} \eta U I \frac{6 \sqrt{3}}{a_{r} b c \pi^{3 / 2}} e^{\left(\frac{-3 x^{2}}{a_{r}^{2}}\right)} e^{\left(\frac{-3 y^{2}}{b^{2}}\right)} e^{\left(\frac{-3 z^{2}}{c^{2}}\right)}$

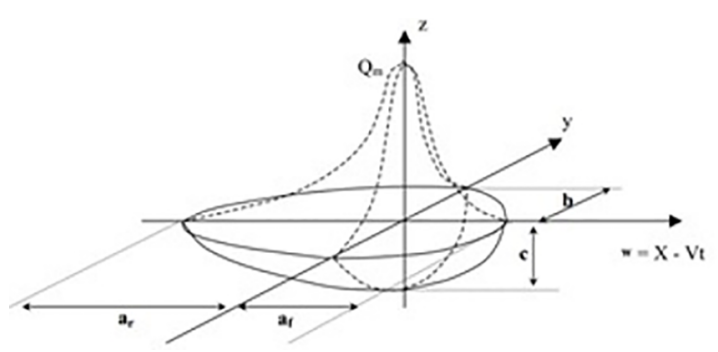

Figure 2. The Double-Ellipsoid Model or the GoldakSource ${ }^{23}$

Table 3. Experimentally measured results of the thermophysical properties of API 5L X80 ${ }^{14}$.

\begin{tabular}{ccccc}
\hline $\begin{array}{c}\text { Temperature } \\
{\left[{ }^{\circ} \mathrm{C}\right]}\end{array}$ & $\begin{array}{c}\text { Thermal } \\
\text { Conductivity } \\
{\left[\mathrm{W} / \mathrm{m}^{\circ} \mathrm{C}\right]}\end{array}$ & $\begin{array}{c}\text { Coefficient } \\
\text { of } \\
\text { Thermal } \\
\text { Diffusivity } \\
{\left[\mathrm{m}^{2} / \mathrm{seg}\right]}\end{array}$ & $\begin{array}{c}\text { Coefficient } \\
\text { of Thermal } \\
\text { Expansion } \\
{\left[{ }^{\circ} \mathrm{C}^{-1}\right]}\end{array}$ & $\begin{array}{c}\text { Specific } \\
\text { Heat }[\mathrm{J} / \\
\left.\mathrm{kg}{ }^{\circ} \mathrm{C}\right]\end{array}$ \\
\hline 0 & 51.062 & $1.400 \mathrm{E}-05$ & $8.50 \mathrm{E}-06$ & 571.235 \\
100 & 51.062 & $1.315 \mathrm{E}-05$ & $8.50 \mathrm{E}-06$ & 571.235 \\
200 & 47.324 & $1.198 \mathrm{E}-05$ & $8.50 \mathrm{E}-06$ & 571.235 \\
300 & 43.840 & $1.087 \mathrm{E}-05$ & $8.50 \mathrm{E}-06$ & 571.235 \\
400 & 40.424 & $9.670 \mathrm{E}-06$ & $8.50 \mathrm{E}-06$ & 614.841 \\
500 & 29.634 & $8.237 \mathrm{E}-06$ & $8.50 \mathrm{E}-06$ & 668.617 \\
550 & 33.546 & $7.358 \mathrm{E}-06$ & $7.50 \mathrm{E}-06$ & 730.831 \\
600 & 26.461 & $5.991 \mathrm{E}-06$ & $7.50 \mathrm{E}-06$ & 780.774 \\
650 & 18.019 & $3.647 \mathrm{E}-06$ & $7.50 \mathrm{E}-06$ & 868.623 \\
700 & 14.874 & $2.865 \mathrm{E}-06$ & $7.50 \mathrm{E}-06$ & 977.091 \\
750 & 11.386 & $2.149 \mathrm{E}-06$ & $-5.00 \mathrm{E}-06$ & 841.431 \\
800 & 14.735 & $2.735 \mathrm{E}-06$ & $-2.50 \mathrm{E}-06$ & 790.265 \\
900 & 14.735 & $2.149 \mathrm{E}-06$ & $5.00 \mathrm{E}-06$ & 608.333 \\
1200 & 14.735 & $2.149 \mathrm{E}-06$ & $8.50 \mathrm{E}-06$ & 681.529 \\
\hline
\end{tabular}

The heat source parameters $\left(a_{\mathrm{f}}, \mathrm{a}_{\mathrm{r}}, \mathrm{b}\right.$ and $\left.\mathrm{c}\right)$ define the size and shape of the two ellipses. These parameters influence the welding process. The energy distribution between the front function and the rear function of the heat source is represented by the variables $f_{f}=\frac{2 a_{f}}{a_{f}+a_{r}}$ and $f_{r}=\frac{2 a_{r}}{a_{f}+a_{r}}$, where $f_{f}+f_{r}=2$. The parameters $U$, I and $\eta$ were obtained through the manufacturer of the welding equipment, according to the thickness and type of material used in the experiments. The parameters $b$ and $\mathrm{c}$ were measured by weld pool macrography of the made joint, Figure 3 . The parameters $\mathrm{a}_{\mathrm{f}}, \mathrm{a}_{\mathrm{r}}, \mathrm{f}_{\mathrm{f}}$ and $\mathrm{f}_{\mathrm{r}}$ are a function of $\mathrm{b}$ and $\mathrm{c}$, where $a_{f}=\frac{1}{2} c$ and $a_{r}=2 c^{3}$.

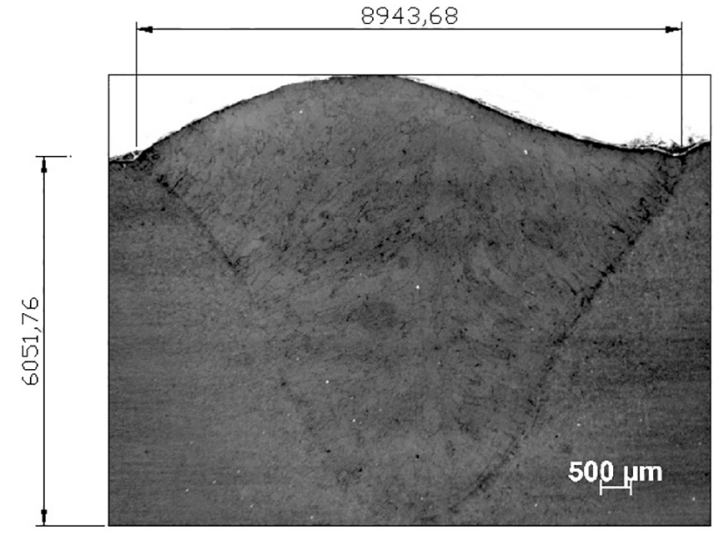

Figure 3. Macrography of the API 5L X80 steel welded joints, after a nital acid attack at $5 \%$ and an increase of $13 \mathrm{X}$

Table 4 shows the geometric parameters of the Goldak heat source used in the work.

Table 4. Values of the heat source parameters.

\begin{tabular}{cc}
\hline Parameter & Value \\
\hline $\mathrm{B}$ & $0.004472[\mathrm{~m}]$ \\
$\mathrm{C}$ & $0.00605[\mathrm{~m}]$ \\
$\mathrm{a}_{\mathrm{f}}$ & $0.003025[\mathrm{~m}]$ \\
$\mathrm{a}_{\mathrm{r}}$ & $0.0121[\mathrm{~m}]$ \\
$\mathrm{f}_{\mathrm{f}}$ & 0.4 \\
$\mathrm{f}_{\mathrm{r}}$ & 1.6 \\
\hline
\end{tabular}

The effect of the filler material in GMAW process was also considered using the element death / element born technique. In this method the elements to be removed are first defined with the properties of the filler material and forming the melted zone of the welded joint. These elements are then removed (element death) from the model and then added (born element) when required during the simulation ${ }^{25}$.

\subsection{Finite element mesh generation and boundary conditions}

Figure 4 shows the three-dimensional mesh of the finite element model DC3D8. It consists of 75,570 elements and 85,822 nodes and was estimated after the convergence tests. Then, the mesh was refined in the melted zone (MZ) and in the heat-affected zone (HAZ). The time increment used was $0.001 \mathrm{~s}$ and a convergence criterion of $0.1^{\circ} \mathrm{C}$. A mechanical boundary condition is available in the ABAQUS/ENCASTRE software; it was set in the lower front edge and in the lower back edge. This thereby ensures absence of degrees of freedom in the model, Figure 5. The boundary condition model was implemented to represent the specimen fixed mechanically. 


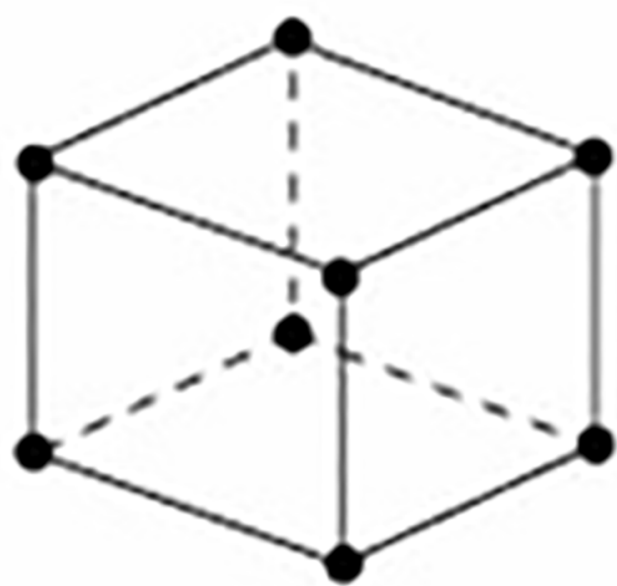

Figure 4. Finite Element DC3D8

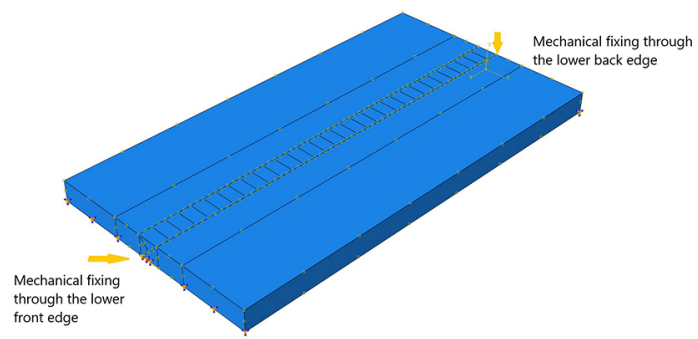

Figure 5. Boundary conditions for mechanical attachment

\section{Measurements by Thermography}

In order to validate the temperature distribution model on the other side of the welding, infrared thermography (IR) has been chosen since it permits measurements at elevated temperature and the results obtained are of high precision ${ }^{26}$, Figure 6.

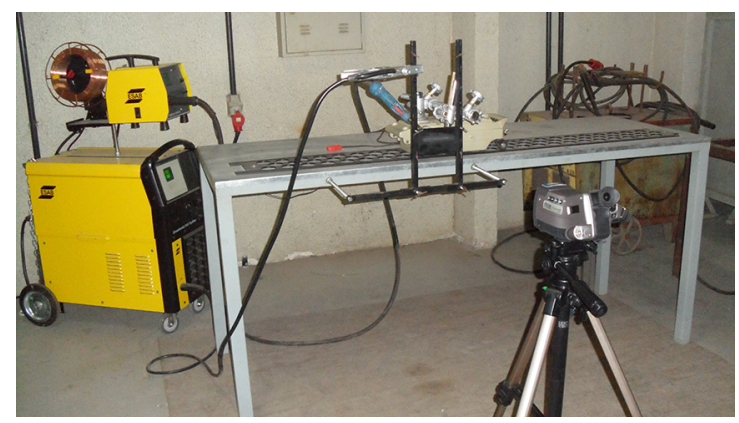

Figure 6. Experimental bench for IR measurements. The infrared images were recorded on the backside of the absorbing part

The FLIR ThermaCAM S45 thermographic camera was used. The camera uses a Focal Plane Array (FPA) detector, which is able to capture wavelengths between 7.5 and 13 $\mu \mathrm{m}$ of electromagnetic spectrum at a resolution of $320 \mathrm{x}$ 240 pixels, totaling 76,800 unrefrigerated microbolometer sensors. The camera was set perpendicular to the object in order to optimize the reception of thermal waves.
The temperature indicated by the thermal camera has a strong dependence on emissivity. This is the most important feature of the surface of an object and that affects the amount of radiant energy. The emissivity is a function of temperature of the object, the surface roughness, the wavelength emitted by the radiation and the camera angle with respect to the object. The emissivity $(\varepsilon)$ value used in this study is $0.9134 \pm 0.068$ and the present author in a previous work estimated $\mathrm{it}^{13}$. However, the emissivity value set in the camera was 0.91 . It may be mentioned that other authors as well ${ }^{5,26,27}$ have reported emissivity values at 0.9 .

Figure 7 shows the emissivity as a function of temperature and Figure 8 shows emissivity distribution ${ }^{18}$.

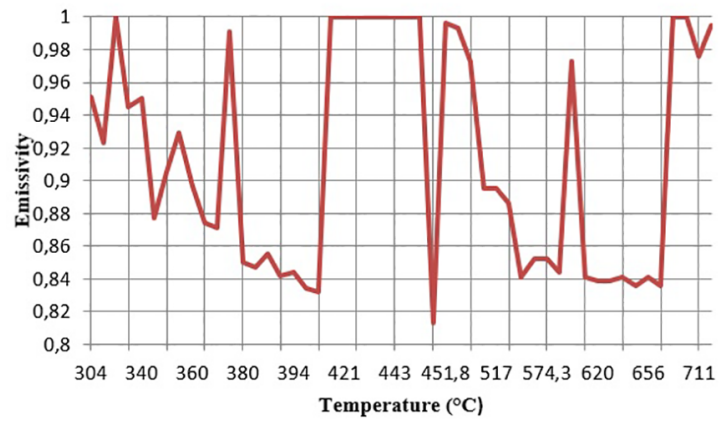

Figure 7. The graph of emissivity versus temperature

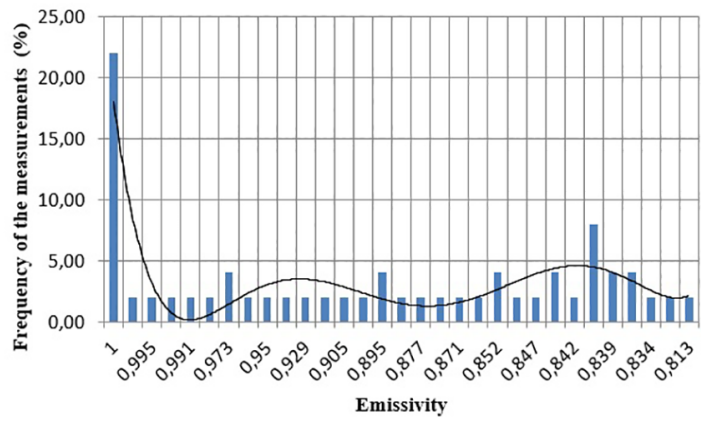

Figure 8. Graph of the emissivity statistic distribution

\section{Results and Discussion}

\subsection{Temperature field image}

The temperature distribution was measured on the opposite side of the welding, specifically in the middle region of the weld melt line. Figure 9 shows a schematic arrangement of the technique.

The temperature fields and thermal cycles obtained experimentally and numerically show a high degree of compatibility, Figure 10.

\subsection{Analyses by FEM and thermography}

Figure 11 compares the numerical results obtained by FEM to those obtained by thermal imaging.

Comparing experimental and the numerical results show that the all points mentioned in Figure 11 present 

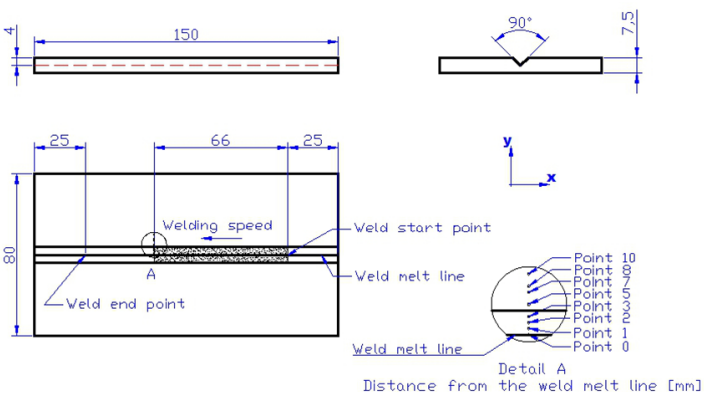

Figure 9. Layout of the specimen indicating points for thermal cycles. The zero point is found at the center of the weld melt line and $66 \mathrm{~mm}$ away from the initial welding point

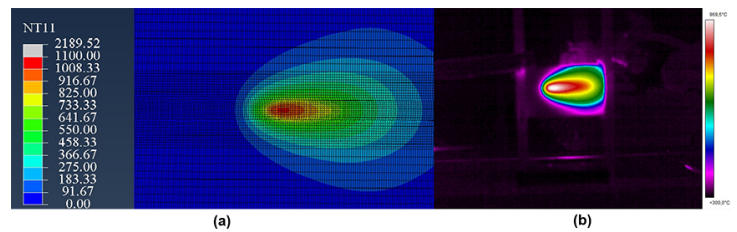

Figure 10. Photography of temperature fields after a distance of $66 \mathrm{~mm}$ covered by the welding torch, where a) FEM and b) IR. Both pictures represent the welding torch moving from the right to the left direction of the paper

similar heating cycles and peak temperatures. Whereas for the cooling cycles up to a temperature of $300 \mathrm{C}$ the curves behave similarly but after about $300 \mathrm{C}$, there is a marked discrepancy between the experimental and numerical results. Note that at about $300 \mathrm{C}$ the FEM curve drops sharply. This disparity occurs because the mathematical model consider the mass of the welded material as infinite. The entire region can be considered as unresponsive to the said validation considering that in these temperature ranges there is not any microstructural change in the base metal.

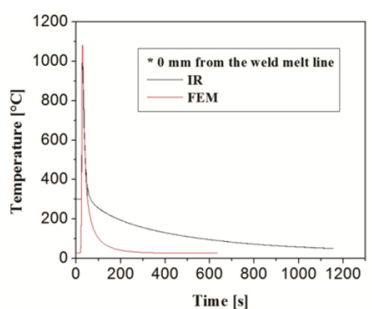

(a)

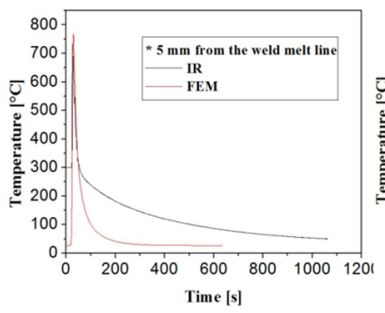

(e)

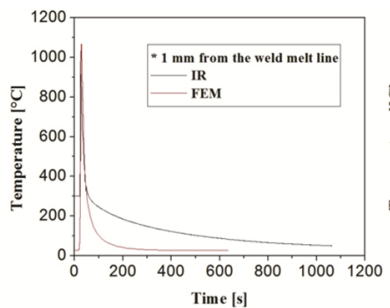

(b)

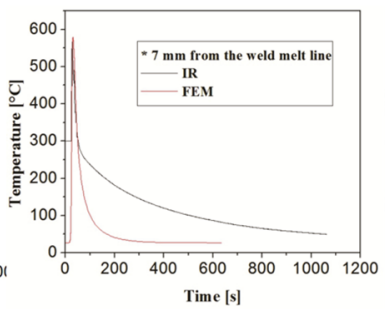

(f)

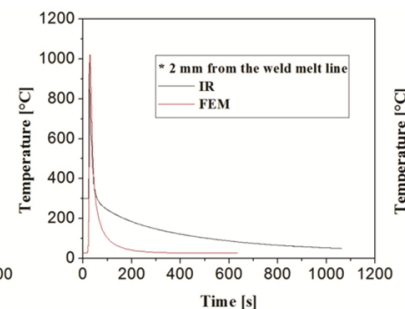

(c)

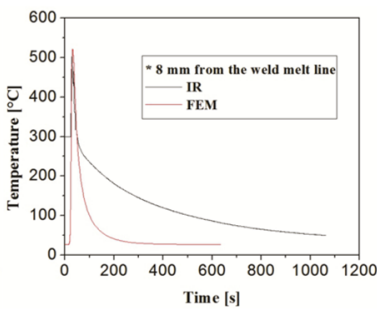

(g)

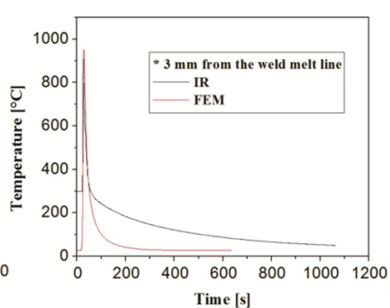

(d)

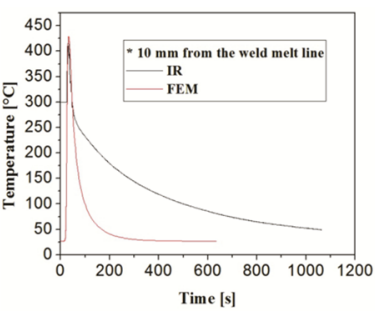

(h)

Figure 11. Numerically (FEM) and experimentally (IR) measured thermal cycles and their respective relative distances to the weld melt line: a) $0 \mathrm{~mm}$, b) $1 \mathrm{~mm}$, c) $2 \mathrm{~mm}$, d ) $3 \mathrm{~mm}$, e) $5 \mathrm{~mm}$; f) $7 \mathrm{~mm}$, g) and h $8 \mathrm{~mm}) 10 \mathrm{~mm}$ 
model and experimental results diminishes. This is due to the fact that the temperature at this location is below $500 \mathrm{C}$ and phase transition does not occur.

As such, thermography is a very reliable technique that allows researchers to work with the variables influencing the heat input calculations in a more assertive manner. However, the mathematical modeling is quite meticulous and the results may be distorted if any small error in the input data.

Important factors that influence the temperature field obtained from the FEM and IR system are: 1) Efficiency of welding acceptable in GMAW varies from 0.75 to $0.95 \%$. This index significantly influences the FEM results; 2) Influence of emissivity in the range 0.9 and 0.99 is significant in the IR technique; 3 ) Alignment check of automation and specimen geometry ensures reliable results in both techniques.

The numerical simulation can provide the temperature distribution on the front face of the weld (as shown in Figure 12). However, the thermographic technique cannot be employed in the temperature range of the electric arc (above $20.000 \mathrm{~K}$ ).

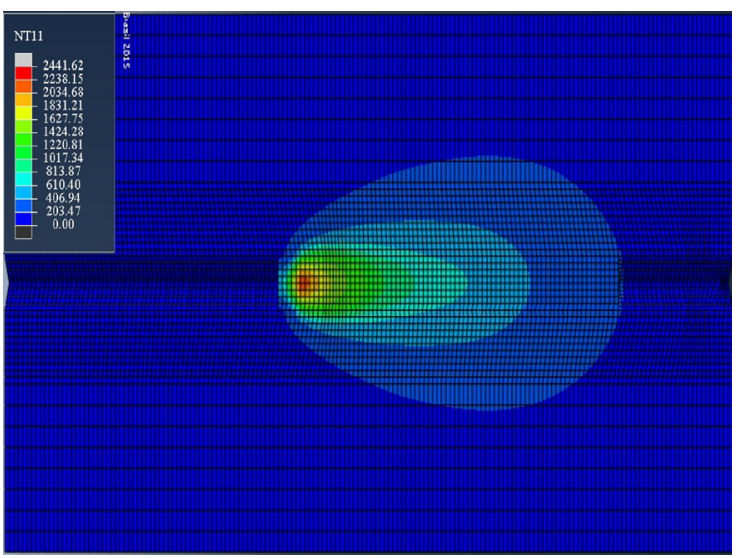

Figure 12. Temperature distribution from the model in the welding plane

\section{Conclusions}

1) The comparison of experimental and numerical results show that the thermal cycles on all selected points are almost identical. However in the cooling phase there is a good agreement only until about $300^{\circ} \mathrm{C}$.

2) The peak temperature is well represented by the numerical model from $0,1,2,3,5$ and $10 \mathrm{~mm}$ measured from the weld melt line. The maximum error in this interval was in the order of $10 \%$.

3) At 7 to $8 \mathrm{~mm}$ from the weld melt line, the infrared thermography observe errors of $15.92 \%$ and $22.46 \%$ respectively.

4) The temperature fields and thermal cycles obtained by the numerical model and thermography (at the rear face of the material) showed good agreement.
5) The results of the simulation show that the model is very sensitive to the welding parameters and small variations of it may result into absurd conclusions. However simulation model can be used as a convenient tool to investigate the effect of welding parameters in the GMAW process. Further experiments with other welding parameters should be performed.

6) Infrared thermography along with numerical simulation form a solid basis for the study of temperature distribution during welding, and it is an important factor to know as it influences distortion and residual stresses in metallic structures.

\section{Acknowledgment}

This work was partly funded by Brazilian research councils CAPES and CNPq.

\section{References}

1. Masubuchi K. Analysis of Welded Structures. Residual Stress and Distortion and Their Consequences. Pergamon Press: Oxford/New York. 1980. p. 33

2. Parlane AJA, ed. Residual Stresses and Their Effect. London: The Welding Institute; 1981. 55 p.

3. Yaghi AH, Hyde TH, Becker AA, Sun W, Hilson G, Simandjuntak $\mathrm{S}$, et al. Comparison between Measured and Modelled Residual Stresses in a Circumferentially Butt-Welded P91 Steel Pipe. Journal of Pressure Vessel Technology. 2010;132(1):011206.

4. Yaghi AH, Tanner DWJ, Hyde TH, Becker AA, Sun W. Abaqus Thermal Analysis of the Fusion Welding of a P92 Steel Pipe. In: Simulia Customer Conference; 2011 May 17; Barcelona, Spain. Dassault Systèmes; 2011. p. 622-638.

5. CamilleriD, Gray TGF, Comlekci T. Use of Thermography to Calibrate Fusion Welding Procedures in Virtual Fabrication Applications. In: Proceedings of Inframation; 2004; Las Vegas, NV, USA.

6. Lee $\mathrm{CH}$, Chang KH. Temperature fields and residual stress distributions in dissimilar steel butt welds between carbon and stainless steels. Applied Thermal Engineering. 2012;45-46:3341. DOI: $10.1016 /$ j.applthermaleng.2012.04.007

7. Attarha MJ, Sattari-Far I. Study on welding temperature distribution in thin welded plates through experimental measurements and finite element simulation. Journal of Materials Processing Technology. 2011;211(4):688-694.

8. Chiumenti M, Cervera M, Salmi A, Saracibar CA, Dialami N, Matsui, K. Finite element modeling of multi-pass welding and shaped metal deposition processes. Computer Methods in Applied Mechanics and Engineering. 2010;199(37-40):2343-2359.

9. Deng D, Murakawa H. Prediction of welding distortion and residual stress in a thin plate butt-welded joint. Computational Materials Science. 2008;43(2):353-365.

10. Gery D, Long H, Maropoulos P. Effects of welding speed, energy input and heat source distribution on temperature variations in butt joint welding. Journal of Materials Processing Technology. 2005;167(2-3):393-401. 
11. Michalski LK, Eckersdorf J, Kucharski J, McGhee J. Pyrometers Classification and Radiation Laws. In: Michalski LK, Eckersdorf J, Kucharski J, McGhee J. Temperature Measurement. 2nd ed. Chichester: John Wiley \& Sons; 2013. p. 152-162.

12. Bhadeshia HKDH. Developments in martensitic and bainitic steels: role of the shape deformation. Materials Science and Engineering: A. 2004;378(1-2):34-39.

13. Francis JA, Bhadeshia HKDH, Withers PJ. Welding residual stresses in ferritic power plant steels. Materials Science and Technology. 2007;23(9):1009-1020.

14. American Welding Society (AWS). Specification for Carbon Steel Electrodes and Rods for Gas Shielded Arc Welding. AWS A5.18. Miami: AWS; 2001.

15. ASME. Boiler and Pressure Vassel Code. Section II - C, Vol. 49, SFA-5.18 and SFA 5.20. New York: ASME; 2001.

16. Marques PV, Modenesi PJ, Bracarense AQ. Soldagem: Fundamentos e Tecnologia. Belo Horizonte: Editora UFMG; 2011.

17. Wainer E, Brandi SD; Homem de Mello FD. Soldagem: Processos e Metalurgia. São Paulo: Edgard Blücher; 1992.

18. Rocha EJF. Uso da Termografia na Análise do Resfriamento de Chapas Soldadas. [Dissertation]. Recife: Department of Mechanical Engineering, Federal University of Pernambuco; 2012.

19. Antonino TS, Guimarães PB, Alécio RA, Yadava YP, Ferreira RAS. Measurements of the Thermophysical Properties of the API 5L X80. Materials Sciences and Applications. 2014;5(8):617627. DOI: $10.4236 / \mathrm{msa} .2014 .58064$
20. Brickstad B, Josefson BL. Parametric study of residual stresses in multi-pass butt welded stainless steel pipes. International Journal of Pressure Vessels and Piping. 1998;75(1):11-25.

21. Hibbitt, Karlsson \& Sorensen. Sorenson Inc. Abaqus User Subroutines Reference Manual. Version 6.7. USA. "DFLUX" Section 1.1.3, "USDFLD" Section 1.1.40. Providence: Hibbitt, Karlsson \& Sorensen; 2007.

22. Jiang WC, Wang BY, Gong JM, Tu ST. Finite element analysis of the effect of welding heat input and layer number on residual stress in repair welds for a stainless steel clad plate. Materials \& Design. 2011;32(5):2851-2857. DOI: 10.1016/j.matdes.2010.12.037

23. Goldak J, Chakravarti A, Bibby M. A new finite element model for welding heat sources. Metallurgical Transactions B. 1984;15(2):299-305.

24. Goldak JA, Akhlaghi M. Computational Welding Mechanics. New York: Springer; 2005. p. 30-35.

25. Hansen JL. Numerical Modelling of Welding Induced Stresses. [Thesis]. Lyngby: Technical University of Denmark, Department of Manufacturing Engineering and Management; 2003. 180 p.

26. Zeng Z, Wang L, Wang Y, Zhang H. Numerical and experimental investigation on temperature distribution of the discontinuous welding. Computational Materials Science. 2009;44(4):1153-1162.

27. Gannon L, Liu Y, Pegg N, Smith M. Effect of welding sequence on residual stress and distortion in flat-bar stiffened plates. Marine Structures. 2010;23(3):385-404. 